\title{
MAKING PEACE WITH MORAL IMPERFECTION
}

\author{
THE PROBLEM OF TEMPORAL ASYMMETRY
}

\section{Camil Golub}

7 He FOLlowing SCENARIO should be familiar to many readers. Someone believes that they made a significant moral mistake at some point in L their life. They strongly prefer not to make similar mistakes again. And yet, thinking about what might have been, they do not wish that they had done things differently in the past. Here are some examples:

Acting: Greta accepted an acting gig with a director who she knew had been accused of sexual misconduct. She believes that it was wrong of her to take the job, and would not make a similar decision again. However, looking back, she does not wish that she had never worked with that director. ${ }^{1}$

Lying: Tyler lied about his credentials on a job application years ago. $\mathrm{He}$ believes it was wrong of him to lie, and has resolved not to make similar mistakes again. However, he does not wish that he had never lied on that job application.

How can people like Greta and Tyler rationally make peace with their past moral failings, while committing to avoid similar mistakes in the future? This is what I call the problem of temporal asymmetry for our attitudes toward moral imperfection.

Note that, by making peace with a moral mistake, I mean having a retrospective preference for one's actual life path, when comparing it to nearby worlds in which one would not have made that mistake. Similarly, I take regret for a past mistake to be a retrospective preference for the closest world in which one did not make that mistake. Such global preferences about the past, which concern entire life paths, should be distinguished from local retrospective preferences,

1 This example is inspired by a New York Times interview with Greta Gerwig, in which she discussed her conflicted feelings about a similar episode in her career. Nevertheless, it should be treated as fictional. 
e.g., wishing that a particular event had not happened, considering it in isolation, and holding fixed everything else about one's life. I will have little to say about the second type of preference in what follows. ${ }^{2}$

Preferring retrospectively one's actual life path is also different from finding emotional closure with the past, and regret as a retrospective preference should not be confused with the affective states typically associated with it, such as guilt and shame. Someone can make peace with a moral failing, in the sense described above, while still thinking about what might have been, and even feeling guilty or ashamed about that mistake. I do not mean to dismiss the significance of such emotions in our ethical lives, but I will focus on preferences regarding moral imperfection because they are more clearly subject to norms of rationality, and they give rise to our puzzle: How can we rationally prefer our imperfect past, while preferring to do the right thing in the future? ? $^{3}$

I should also clarify what I mean by moral mistake. I have in mind cases where one did something morally wrong, and the moral disvalue of said act was not outweighed by the agent's self-interest or any other kind of nonmoral value, such as one's practical identity or ground projects. ${ }^{4}$ In other words, I am focusing on cases where, by the agent's own lights, one ought to have done the morally right thing, all things considered.

Moreover, I am not talking about cases where one had subjective reasons to do the morally right thing in the past, i.e., reasons relative to what one could reasonably expect at the time of action, but retrospectively one can identify objective reasons that justify one's moral transgression, such as the long-term positive impact of that mistake on the agent's well-being. Rather, I am focusing on cases where the agent believes that she objectively ought to have done the right thing, and yet retrospectively prefers the life path in which she acted wrongly, while wanting to avoid similar mistakes in the future.

Finally, when I say that the agent wants to do the right thing if she is to face similar circumstances again, I have in mind cases where the overall balance between moral reasons and other types of value would be the same as for the

2 In Wallace's terms, I will focus on all-in regret, rather than regrets, for past mistakes (The View from Here).

3 In taking regret to be a retrospective preference, I am following, e.g., Harman, “'I'll Be Glad I Did It' Reasoning and the Significance of Future Desires” and “Transformative Experiences and Reliance on Moral Testimony"; and Wallace, The View from Here. This conception of regret diverges from some recent literature in moral psychology, where regret is understood as an emotion. See, e.g., Morton, "Cousins of Regret”; and Priest, "Reasonable Regret."

4 See Williams, "Persons, Character, and Morality”; Wolf, "Moral Saints"; and Frankfurt, "The Importance of What We Care About," for canonical arguments to the effect that moral demands may be outweighed by other types of value in our lives. 
agent's past mistake. So the temporal asymmetry in Acting, for instance, cannot be explained by the fact that Greta's retrospective preference concerns an entire section of her life, while the prospective preference focuses on a particular action. By hypothesis, Greta wants to do the right thing in the future, even if doing the wrong thing again were to bring the same type of long-term consequences as her past mistake. ${ }^{5}$ How can this prospective attitude be reconciled with Greta's retrospective preference for her actual life path?

A good answer to this problem should accommodate the fact that people often do regret their moral mistakes, and reasonably so. That is, we need an account that would explain why, e.g., Greta's lack of regret is rationally permissible, while allowing that regret for past mistakes is also permissible. Moreover, such regret might even be rationally required if one's moral failings are grave enough. ${ }^{6}$

Here is the answer that I will defend. Two kinds of attachments can justify conservative attitudes about past moral mistakes, without shifting retrospectively the balance of objective reasons for our actions, and without providing equal support for wanting to be morally imperfect in the future: personal attachments to relationships, projects, and other particular valuable things in our past, and a commitment to our biographical identity. That is, we can rationally prefer a life path marked by significant moral failings if we give enough weight to the personal attachments that those mistakes enabled, and to the way in which said mistakes have shaped who we are. But these attachments need not change the fact that we ought to have done the right thing, all things considered, nor need they give us sufficient reason to want to do the wrong thing again in the future. ${ }^{7}$

5 Admittedly, the agent might never be in a position to know that she finds herself in such circumstances, given that this would involve being able to predict the long-term consequences of her actions. But this need not prevent the agent from forming a preference with respect to such circumstances. We can reasonably form preferences concerning situations that we assume would be opaque to us in relevant respects, e.g., if I ever pick a winning lottery ticket, I prefer not to die in a car accident before I find out about it and claim my prize.

6 Of course, this is not the kind of case on which I focus here: I want to make sense of cases like Acting and Lying, where the agents' mistakes are arguably not grave enough to make regret obligatory.

7 The role of identity and personal value in retrospection has been explored before-see Adams, "Existence, Self-Interest, and the Problem of Evil”; Harman, "I'll Be Glad I Did It' Reasoning and the Significance of Future Desires" and "Transformative Experiences and Reliance on Moral Testimony"; Wallace, The View from Here; and Golub, "Personal Value, Biographical Identity, and Retrospective Attitudes." These discussions have focused on how retrospective preferences can diverge from evaluative judgments about the past, where this includes prudential and moral judgments. There has been no comprehensive treatment of the problem of temporal asymmetry for our attitudes toward moral imperfection, including a comparison between the personal value and biographical identity proposal and alternative accounts of such attitudes. This is what my paper will provide. 
In section 1, I will examine some views on how we can reasonably make peace with our moral failings that cannot support a temporal asymmetry in our attitudes, such as the idea that we can rationally prefer our imperfect past from a self-interested standpoint, even if we believe that, all things considered, we ought to have acted morally. This discussion will help show that, in cases that give rise to our puzzle, conservative attitudes about the past must be supported by attachments to particular bearers of nonmoral value, rather than indicating the weight that one gives to certain types of nonmoral value, or any general attitude toward moral imperfection.

In section 2, I will discuss some views on making peace with moral imperfection that do allow for a temporal difference in our attitudes: (i) it is irrational to wish that we had done things differently, because we cannot do anything to change the past; (ii) it is rational to prefer that bad things be in our past rather than our future; (iii) regret for our past mistakes is undesirable because psychologically harmful; and (iv) we can rationally affirm our imperfect past because we learn from our mistakes. None of these proposals, I will argue, properly accounts for our asymmetric attitudes toward moral imperfection. This discussion too will help me isolate some virtues of the view that I favor, such as its ability to account for cases where people reasonably regret their past mistakes.

In section 3, I will elaborate on the positive proposal. In particular, I will say more about the normative force of my claims and the nature of biographical identity, and will briefly address a skeptical challenge to the effect that autobiographical stories are too unreliable to serve as a foundation for conservative attitudes about the past.

\section{TEMPORALLY NEUTRAL VIEWS ON MORAL IMPERFECTION}

Ordinary discourse about morality is full of reminders that we should try to make peace with at least some of our mistakes. We should not be too hard on ourselves. Nobody is perfect. To err is human. Similar ideas about moral imperfection can be found in philosophical literature, usually as part of a broader call to embrace the imperfections in our lives, where this is not limited to our moral flaws.

Cheshire Calhoun, for instance, argues that it is a virtue to adopt an attitude of contentment toward our lives, despite their bad features, insofar as said lives contain plenty of good things that we ought to appreciate. ${ }^{8}$ This disposition to contentment, she says, is enabled by using appropriate expectation frames with respect to what are good enough life conditions, and extends to moral features of

Calhoun, “On Being Content with Imperfection.” 
the world, including our own moral qualities. Michael Sandel holds that striving for perfection, in ourselves or others, indicates a lack of humility or a Promethean desire for mastery over nature, and that we need to learn to accept the givens of human existence. ${ }^{9}$ Similarly, in theorizing about interpersonal love, Vida Yao articulates the notion of grace as love for the qualities of human nature, including the flaws of one's beloved. ${ }^{10}$ This idea would presumably extend to self-love as well, and thus support an attitude of acceptance toward one's own imperfections. ${ }^{11}$

Whatever truth there might be in these ideas, they cannot explain the temporal asymmetry involved in our puzzle. Insofar as we have reasons to be content with our morally imperfect lives, or to accept our flaws as a given of human nature, these reasons would seem to equally apply to our future moral mistakes as well. But again, it seems reasonable to make peace with some of our moral failings while resolving to avoid similar mistakes in the future. We cannot account for this by appealing to a general attitude toward moral imperfection as such.

Calhoun discusses the temporal dimension of contentment, and argues that her view does not condone complacency with respect to one's moral flaws: contentment with how one's life has unfolded so far is compatible, she says, with being motivated to improve oneself in the future.

I agree that this combination of attitudes is rational, but I do not see how Calhoun's view on contentment can account for it. If a conservative preference for one's actual life path is enabled by having an expectation frame according to which one's life has been good enough from a moral standpoint, despite its flaws, why should one not adopt a similar expectation frame with respect to one's future life? ${ }^{12}$

9 Sandel, The Case against Perfection. In defending his conservatism about value, Cohen, "Rescuing Conservatism," also makes some remarks about accepting the given as an attitude worth cultivating. Yao, "Grace and Alienation."

Nietzsche, The Gay Science, offers a characteristically bolder view on this issue. We should not only accept our moral imperfections, he claims, but see them as contributing to the aesthetic value of our lives: "To 'give style' to one's character - a great and rare art! It is practiced by those who survey all the strengths and weaknesses of their nature and then fit them into an artistic plan until every one of them appears as art and reason and even weaknesses delight the eye" (sec. 290).

Calhoun also proposes that we distinguish between expectation frames that govern our emotions toward how things are, and normative standards that determine what we should prefer and how we should act: this explains, she says, how we can be emotionally content with how our lives have gone so far while wanting to improve our condition for the future. But insofar as Calhoun is only interested in contentment as an emotion, her view will not offer a solution to the puzzle discussed in this paper, which concerns preferences about moral 
A different account of our conservative attitudes about the past would go as follows: we can reasonably prefer our actual life path from a self-interested standpoint, even if we accept that, all things considered, moral considerations outweighed the rational significance of self-interest, so we ought to have done things differently. In other words, we can compartmentalize retrospection into different sets of attitudes-e.g., self-interested, moral, all-things-consideredand this might explain how retrospective preferences can rationally diverge from normative judgments about the past. ${ }^{13}$

However, this self-interest diagnosis cannot account for the temporal asymmetry either: if the fact that a morally imperfect life was better for us gives us reason not to wish that things had gone differently, we should have equally strong reason to pursue a similar life path again. Nor is it plausible to say that we form our conservative preferences about the past from a self-interested perspective, but then adopt a moral or all-things-considered perspective when considering what we want to happen in the future. In cases like Acting or Lying, there seems to be no such shift between evaluative standpoints.

There is a significant difference between our evaluative perspectives on past and future moral mistakes, but this is not a contrast in how we weigh different types of value. When thinking about the past and preferring that our life unfolded as it did, despite our judgment that we ought to have done things differently, this conservative attitude is not explained by the weight we give to self-interest or any other type of nonmoral value in our preferences. Again, if this were the explanation, the problem of temporal asymmetry would remain unsolved: by hypothesis, the agent wants to do the right thing in future cases that would involve the same balance between morality and other kinds of value.

In order to solve our puzzle, we need to focus instead on particular things in our past to which we can be reasonably attached, rather than the weight we give to any type of value. More precisely, on the view that I defend, particular bearers of personal value and specific ingredients of our biographical identity

imperfection. And if we switch our attention to normative standards governing preferences, again it is not clear how Calhoun's idea of appropriate expectation frames can help solve the problem of temporal asymmetry. Why should we adopt standards according to which our lives have been morally good enough so far, despite the mistakes that we have made, but would not be good enough were we to make similar mistakes again?

13 This is how Parfit explains the divergence between moral judgments and retrospective preferences in cases that give rise to the non-identity problem: e.g., it can be rational for someone not to regret his own existence from a self-interested perspective, while accepting, from a moral standpoint, that his mother made a mistake by having him at a very young age (Reasons and Persons). 
are sources of support for conservative retrospective attitudes, and the temporal asymmetry is explained by the fact that we cannot yet be similarly attached to particular things in our future.

I will develop this proposal in section 3 . But first, let me examine other views that allow for a temporal asymmetry in our attitudes toward moral imperfection. I will argue that these views do not provide good answers to our puzzle: they either cannot explain why regret for past mistakes is often rationally permissible, or they do not properly account for some cases where people do not regret their past mistakes but want to be better in the future.

\section{WHAT IS SPECIAL ABOUT THE PAST?}

Someone might think that we do not need to explore what we value in our lives and how we value it in order to explain why it is reasonable to feel differently about our past and future moral failings. Perhaps the explanation is simpler: it is irrational to wish that we had not made the mistakes that we made, because we cannot do anything to change the past. But our future is still open: it is largely up to us whether we will make similar mistakes again. So it is rational to want to be morally better in the future. We could call this response to the puzzle fatalism about the past. ${ }^{14}$

The problem with this proposal is that we can rationally prefer that things had gone differently in our lives. In particular, we can reasonably regret our past moral mistakes. Coming up with examples of this is all too easy. For instance, I suspect that Christopher Wylie wishes that he had not contributed to the election of Donald Trump by working for Cambridge Analytica, and this is a reasonable attitude to have. The right account of these matters should make sense of conservative retrospective attitudes while allowing that revisionary preferences about the past are rationally permissible as well, and might even be required in some cases. Focusing on the temporal structure of agency is too blunt a tool to deliver this result.

Perhaps, though, a more moderate version of fatalism about the past could do the job. Suppose someone suggested that revisionary preferences about the past are rationally permissible, but only for grave moral mistakes. When it comes

14 This should be distinguished from a global fatalism according to which everything that has happened and will happen to us is predetermined, so it is irrational to want the world to conform to our desires-a view that is often attributed to ancient Stoics like Seneca and Epictetus. Global fatalism might support an attitude of resignation with respect to our moral flaws, but it would not help address the puzzle of temporal asymmetry. I should note in this context that Irvine, A Guide to the Good Life, interprets the Stoics as defending fatalism about the past rather than global fatalism. 
to mistakes that are below a certain threshold of severity, it is irrational to wish that things were different.

However, this proposal will not work either. First, the idea of a threshold beyond which regret for past mistakes is rationally permissible does not square well with what seemed to be the core underlying claim of fatalism about the past: that it is irrational to want the impossible. And even putting aside its ad hoc character, this moderate version of fatalism is still too strong, as it entails that regret is irrational for moral mistakes that fall below the given threshold of gravity. This is implausible. For instance, in a case like Acting, Greta would not be making any mistake if she did regret her past mistake and her actual life path.

What we need, again, is an account according to which both regret and the lack thereof are permissible attitudes with respect to past moral mistakes, at least insofar as said mistakes were not too grave. Fatalism about the past, in either of its forms, cannot have this permissivist upshot.

The temporal asymmetry in our attitudes toward moral imperfection might also remind us of the bias toward the future famously examined by Derek Parfit: we tend to prefer that bad things be in our past rather than our future. If we could show that this tendency is actually rational and not a mere bias, perhaps this would help solve the problem of temporal asymmetry. ${ }^{15}$ Not directly, because the question we have been discussing is not about choosing between the past and the future as the temporal location for our moral mistakes. ${ }^{16}$ But even so, if the temporal bias were rational, this would seem to entail that we have weaker reasons to care about our past moral failings than about our future mistakes, which might account for the cases in which we are interested: e.g., if it is rational for Tyler to give less weight to the moral disvalue of his past mistake than to a similar mistake in the future, then his self-interest and other types of nonmoral value might outweigh moral considerations retrospectively but not prospectively.

However, this is not a good account of the temporal asymmetry. It is implausible that what goes on in cases like Acting and Lying is that people care less about their past mistakes than about their future ones. Or, to put it differently, it would seem perfectly reasonable for someone to treat his past and future moral mistakes as equally important, and yet to affirm his actual life path while wanting to be morally better in the future. The rationality of these asymmetric attitudes is

Parfit, Reasons and Persons. I will not discuss here any attempts to justify the bias toward the future. But see, e.g., the evolutionary justification proposed by Horwich, Asymmetries in Time; and Dyke and Maclaurin, “"Thank Goodness That's Over,” for a critical response. 
still left unexplained. ${ }^{17}$ The proposal that I defend fills this explanatory gap: it is not because we care less about our past mistakes that we can rationally affirm our actual life paths, but because we are attached to particular valuable things in our past and committed to our biographical identity, while our prospective attitudes are not influenced by such attachments.

Another intuitively plausible response to our puzzle would be that regret for our past mistakes is undesirable because psychologically harmful. Moreover, it might be argued, regret is inimical to the goal of avoiding moral mistakes in the future, because it undermines our confidence and self-worth. We need to forgive ourselves in order to find the strength to improve, as well as for the sake of our well-being. ${ }^{18} \mathrm{~A}$ virtue of this proposal is that it can allow for the rational permissibility of regret in cases where its instrumental disvalue is outweighed by the moral disvalue of our past mistakes.

However, these pragmatic considerations do not seem to capture what goes on in the relevant cases either. Our main reasons for affirming our imperfect past intuitively concern the content of our life path as such, rather than the prospective benefits of making peace with our mistakes: we look back at our lives, discover that we are attached to some of their particular ingredients, and therefore do not wish that things had gone differently. My proposal makes good on this intuition. Moreover, remember that we have been talking about regret as a retrospective preference, rather than about the various affective states typically associated with this preference, and mere retrospective preferences are arguably much less harmful than emotions such as guilt or shame.

A different pragmatic approach to the temporal asymmetry would focus on the instrumental value of moral mistakes for our moral growth. We learn from our mistakes, it might be argued, and this gives us reason to affirm our imperfect life path, without supporting a preference for making similar mistakes again, given that doing so would not deliver the same educational benefits.

Now, it may well be true that some moral mistakes enable our access to certain moral truths or help build our character. But this cannot be the full story, or

17 Moreover, insofar as it is rational to care more about how well our lives will go in the future than about our past well-being, it is even more mysterious why we would prefer to do the morally right thing in the future while not wishing that we had acted rightly in the past, given that the balance between moral demands and self-interest is assumed to be the same from both perspectives.

18 See, e.g., Lieberman, "Why You Should Stop Being So Hard on Yourself," for a summary of recent psychological research on the negative impact of self-criticism. See also Card, The Atrocity Paradigm, who suggests that some self-forgiveness may be required for self-respect, even for evil deeds (210). Thanks to an anonymous reviewer for drawing my attention to this passage. 
even the main story, about our asymmetric attitudes toward moral imperfection, as it does not account for two important categories of cases. First, even when we do learn from our mistakes, we can still reasonably affirm our actual past when comparing it to a life path in which we would have made the same moral progress through other means, e.g., by learning from others. ${ }^{19}$ Second, some moral mistakes may not lead to any gain in moral knowledge or any improvement in our character. For instance, we might have already known that we ought to have done the right thing, but we succumbed to temporary temptations. Or we lacked some relevant moral knowledge in the past, which we gained in the meantime, but in ways that had nothing to do with our past mistakes. (This might be the most common scenario for people who contemplate their past moral failings.) In all these cases, we can reasonably prefer our actual life path while wanting to be better in the future. The personal value and biographical identity proposal can account for this wide range of cases where the temporal asymmetry is present, while the epistemic diagnosis cannot.

\section{PERSONAL VALUE AND BIOGRAPHICAL IDENTITY}

Two sources of support for conservative attitudes about the past can explain the temporal asymmetry in our attitudes toward moral imperfection: personal attachments and a commitment to our biographical identity. That is, we can reasonably affirm our morally imperfect lives if our mistakes have enabled some of our significant relationships or projects, or other attachments to particular valuable things, or if they have shaped who we are in a biographical sense. Such attachments can allow us to make peace with our past mistakes without shifting retrospectively the balance of reasons for our actions: it can still be the case that we objectively ought to have done the right thing, all things considered. ${ }^{20}$ Moreover, our prospective attitudes toward moral imperfection cannot be shaped to the same extent by personal attachments that we might develop as a result of making moral mistakes, or by things that may become part of our identity in the future. This is how the problem of temporal asymmetry is resolved.

To use the Acting example again, Greta may reasonably prefer her actual life

19 Note, moreover, that when we do learn something valuable from our mistakes, but similar future mistakes would not deliver similar benefits, this means that there is a difference in objective reasons between our past circumstances and our future ones. So, strictly speaking, this is not the kind of case on which I have been focusing: I want to make sense of our asymmetric attitudes in cases where the balance of objective reasons would be the same for a future mistake as for a past mistake.

20 See Salow, "Partiality and Retrospective Justification," for a discussion of whether personal attachments can retrospectively justify one's actions. 
path because the mistake that she made enabled a significant relationship to which she is now attached or has led to other events and experiences that are central to her identity. She may also predict that doing the wrong thing again would enable a new significant relationship or shape a new chapter of her life story, and that if this were to happen, she would then have sufficient reason to retrospectively affirm her actual life path once more. But those possible future attachments do not presently give Greta equally strong reasons to want to be morally imperfect. To be clear, prospective attachments can factor into the balance of reasons for our actions, e.g., someone might decide to have a child because she sees the parent-child relationship as distinctly valuable. But such merely possible attachments do not have the same normative force as our actual attachments to specific aspects of our lives: actual personal attachments matter more than merely possible ones, and in a way that is not reducible to their objective value. I take this feature to be central to the very notion of personal attachment. For this reason, our actual attachments can support a preference for how our life has unfolded, when compared to morally better lives that we could have had, while the prospect of similar attachments in the future need not support a preference for making similar moral mistakes again. ${ }^{21}$

Someone might object that this asymmetry in normative force between actual and merely possible attachments, or between actual and possible ingredients of our identity, only shows that our personal attachments and biographical identity do shift the balance of objective reasons for our past actions, which goes against how I described cases like Acting and Lying in setting up the puzzle. For example, it might be argued that Greta can now recognize reasons for her past moral mistake that were not available to her at the time of action, such as the actual personal attachments enabled by that mistake.

However, the special weight carried by actual attachments in retrospection goes beyond the objective reasons that someone had at a time when those attachments did not yet exist. Again, this is not to deny that prospective attachments can affect the balance of objective reasons for our actions. The fact that a moral mistake is likely to enable a significant personal attachment can provide some reason to commit that mistake. Similarly, the personal attachments enabled

To be clear, I am not suggesting that our actual attachments only matter when we think about the past. Existing personal attachments and a commitment to our actual identity can also play a normative role when we deliberate about the future, and in particular they can favor being morally imperfect in the future, e.g., we may be moved to make choices that fit who we are, or that privilege the relationships and projects that we especially care about, rather than comply with impersonal moral demands. But in most cases, we can give proper weight to our existing attachments and our actual identity while avoiding moral mistakes that we made in the past. 
by a past mistake can be retrospectively recognized as favoring that mistake, insofar as there is objective value in developing such attachments. But when personal attachments become actual, they gain a normative significance that they did not have before and can support preferences that are not aligned with our judgments of value. This is why, for instance, it is reasonable for Greta to form the following combination of attitudes: I retrospectively prefer my actual life path because the decision to work with director $X$ has enabled a significant relationship of mine and has shaped who I am, but it is still true that, all things considered, I objectively ought to have done the right thing.

This proposal allows for reasonable regret for what might have been-not only in cases of grave moral mistakes, where regret might be rationally required, but also in cases like Acting and Lying, where lack of regret is permissible. In other words, the moral disvalue of our mistakes may sometimes decisively outweigh our personal attachments and the commitment to our identity, while in other circumstances neither regret nor affirmation is rationally required: in those cases, it is up to us whether to take facts about our personal attachments or biographical identity as good enough reasons for lack of regret.

Someone might agree that the temporal asymmetry is explained by the special weight we give to particular things in our past, and still wonder why only bearers of personal value and ingredients of our biographical identity can play this normative role. Why not include all particular valuable things in our lives among the sources of support for conservative attitudes about the past?

The answer is that, unlike other forms of valuing, personal attachments and the commitment to one's identity are constitutively governed by a norm of non-fungibility. For instance, someone is not really attached to a significant project in his life if he is willing to replace it with something of greater value as soon as he has the chance. Similarly, if a person is genuinely committed to who she is, she must be disposed to prefer that identity to other identities that she might have, including morally better identities. ${ }^{22}$ This norm of non-fungibility

This is not to say that someone who is committed to her identity must be disposed to prefer that identity at all costs, or over any other alternative. But she must give some weight to the fact that this is who she is, when comparing her actual identity to better alternatives. The same holds for personal attachments to persons, projects, etc.: non-fungibility does not entail that we should treat the things we are attached to as absolutely irreplaceable, no matter how great the difference in value is between them and other possible objects of attachment. Moreover, how much weight we should give to our actual attachments will depend on the strength and quality of those attachments, e.g., someone whose marriage is coming apart may reasonably ponder ending it and seeking a new romantic relationship that would be more valuable. But even in such cases, we will still give some special weight to our actual attachments, when comparing them with merely possible ones-if we do not, then those 
does not apply, for instance, to all bearers of prudential value. The fact that something contributed to my well-being is not a reason to prefer it to other things that would have made my life even better. And there is no reason to assign greater weight to things that have actually made my life good for me than to things that will equally contribute to my well-being in the future. This is, again, why an explanation in terms of self-interest cannot resolve the problem of temporal asymmetry, and more generally why not all particular valuable things in our past give us reason for conservative attitudes. ${ }^{23}$

Personal value has been much discussed in contemporary moral philosophy, including its role in retrospection. ${ }^{24}$ While the influence of our self-conception on our retrospective attitudes has also been explored before, less has been said about what this notion of identity amounts to and its normative force. ${ }^{25}$ Let me end, then, with some remarks on the nature of biographical identity and how it interacts with our retrospective attitudes and moral judgments, and by addressing a skeptical worry about its ethical significance.

It has become common to distinguish between metaphysical and ethical notions of personal identity: metaphysical questions about our essence and persistence as individuals do not seem to concern the same type of identity as ethical questions about authenticity and who we are in a qualitative sense. ${ }^{26}$ A non-metaphysical type of identity is involved in conservative retrospection.

actual attachments have simply ceased to exist. Thanks to John Monteleone for discussion on this issue.

23 Thus, I am rejecting here the conservatism about value defended by Cohen, "Rescuing Conservatism," according to which all particular valuable things give us reason to wish to see them preserved, at the expense of new and better things, insofar as this general conservatism is meant to apply to attitudes about the past as well. Properly arguing against this view goes beyond the scope of my paper, but I should point out that, when discussing a counterexample proposed by David Wiggins, Cohen himself tentatively concedes that his view might be too strong, and that perhaps conservative attitudes should be directed at only certain categories of valuable things.

24 See Scheffler, "Relationships and Responsibilities"; and Kolodny, "Which Relationships Justify Partiality?" for canonical treatments of the ethical significance of personal attachments. Cohen, "Rescuing Conservatism," discusses personal value as a source of support for conservative prospective attitudes. On the role of personal value in retrospection, see Adams, "Existence, Self-Interest, and the Problem of Evil"; McMahan, "Preventing the Existence of People with Disabilities”; Harman, “I'll Be Glad I Did It' Reasoning and the Significance of Future Desires" and "Transformative Experiences and Reliance on Moral Testimony"; and Wallace, The View from Here.

25 For the influence of our self-conception on our retrospective attitudes, see especially Adams' and Harman's papers cited in the previous footnote.

26 See, e.g., Schechtman, The Constitution of Selves; and DeGrazia, Human Identity and Bioethics. 
More precisely, our conservative attitudes toward our own moral imperfection are often rooted in a commitment to who we are in a biographical or narrative sense. This identity is partly constructed by ourselves, through the stories we tell about our lives, in which we assign a central role to certain events, experiences, etc., but it also depends on objective facts about the world: for instance, being a great soccer player could not be part of my biographical identity, no matter what I told myself, given that I am terrible at this sport. ${ }^{27}$

If we judge that something in our past has become part of who we are and we endorse our biographical identity, this gives us reason to prefer our actual life path, even if we believe that, all things considered, we ought to have pursued a morally better life. Importantly, this applies not only to valuable things in our past: disvaluable things, e.g., experiences of adversity and hardship or even moral mistakes, can also become part of our identity and thus support conservative preferences about the past.

The reasons for conservative attitudes provided by the commitment to our biographical identity are defeasible: if our moral mistakes were grave enough, regret might be rationally required. Indeed, in some cases the fact that a given mistake has come to shape our identity might even strengthen our reasons for regret. Think again of the Christopher Wylie case: it would be reasonable for him to regret not only his work for Cambridge Analytica, but also the fact that this career choice has come to define his identity.

Moreover, even in cases where lack of regret is reasonable, we should allow for reasonable divergence between people's retrospective preferences: for instance, if someone in Greta's position did not assign much weight to her biographical identity and regretted her morally imperfect life path, she need not be making any normative mistake. It is generally our prerogative whether to endorse our biographical identity and how much weight to give it in retrospection—again, at least if our moral mistakes were not too grave.

Someone might worry that our biographical identity cannot serve as a good foundation for conservative attitudes toward the past, given that the stories we

27 This characterization of biographical identity is inspired by the narrative conceptions of identity defended by Schechtman, The Constitution of Selves, and DeGrazia, Human Identity and Bioethics, and by psychological research on life stories and narrative identity, e.g., Cohler, "Personal Narrative and Life Course"; Habermas and Bluck, "Getting a Life"; and Harbermas, "Autobiographical Reasoning." I cannot offer here a full account of biographical identity, including a discussion of the challenges faced by theories like Schechtman's and DeGrazia's, e.g., how exactly to reconcile the idea of narrative identity as our own creation with the thought that the narratives we tell ourselves can be misguided. But I hope that the brief remarks I offer give the reader an intuitive grasp on this notion and the role it plays in retrospection. 
tell about our lives are often unreliable: we tend to ignore events that do not fit our general sense of who we are, particularly when it comes to our moral failings. ${ }^{28}$

In response to this skeptical worry, let me first note that I have been talking about cases where people do acknowledge their past moral failings, rather than ignore those mistakes or reinterpret them away. One cannot make peace with a moral mistake if one does not acknowledge it as a mistake.

However, the worry might persist: even if we see certain events in our past as moral failings, perhaps we find it easy to make peace with these mistakes due to our general tendency to see ourselves retrospectively as better than we actually were, e.g., to ignore other mistakes that we have made and thus misjudge the overall moral value of our lives, or to think that those mistakes were not representative of our character. Thus, the commitment to our biographical identity is not a suitable ground for conservative attitudes, insofar as autobiographical stories are plagued by self-deception. Or so the argument would go.

This is indeed a disquieting thought about the role of biographical identity in retrospection, and I cannot offer here a clear criterion for distinguishing the good cases in which self-told narratives are reliable enough to support conservative retrospection from the bad cases in which they are not. But I do believe that there are good cases, and my thesis about the retrospective import of biographical identity should only be taken to apply to such cases in which we are not vastly deluded about who we are: if the moral mistakes in our past were not too damning, we can reasonably prefer our imperfect life path to alternative lives that would have been morally better but too different, and thus alienated from who we are. ${ }^{29}$

\author{
Rutgers University-Newark \\ camil.golub@rutgers.edu
} of skeptical worries about autobiographical stories.

For helpful comments and discussion, I would like to thank Kati Balog, Andy Cullison, Jason D'Cruz, Raffaella De Rosa, Asia Ferrin, Daniel Fogal, Alida Liberman, Irene Liu, Claudia Mills, Rob MacDougall, Jordan MacKenzie, John Monteleone, Jake Wojtowicz, Mike Zhao, two anonymous reviewers for this journal, and audiences at the Icahn School of Medicine, DePauw University, Trinity College Dublin, and Le Moyne College. 


\section{REFERENCES}

Adams, Robert Merrihew. "Existence, Self-Interest, and the Problem of Evil." Noûs 13, no. 1 (March 1979): 53-65.

Calhoun, Cheshire. "On Being Content with Imperfection." Ethics 127, no. 2 (January 2017): 327-52.

Card, Claudia. The Atrocity Paradigm: A Theory of Evil. Oxford: Oxford University Press, 2002.

Cohen, G. A. "Rescuing Conservatism: A Defense of Existing Value." In Finding Oneself in the Other, 143-74. Princeton: Princeton University Press, 2012.

Cohler, Bertram J. "Personal Narrative and Life Course." Life Span Development and Behavior 4 (1982): 205-41.

DeGrazia, David. Human Identity and Bioethics. Cambridge: Cambridge University Press, 2005.

Dyke, Heather, and James Maclaurin. “'Thank Goodness That's Over': The Evolutionary Story." Ratio 15, no. 3 (September 2002): 276-92.

Frankfurt, Harry. "The Importance of What We Care About." Synthese 53, no. 2 (November 1982): 257-72.

Golub, Camil. "Personal Value, Biographical Identity, and Retrospective Attitudes." Australasian Journal of Philosophy 97, no. 1 (2019): 72-85.

Habermas, Tilmann. "Autobiographical Reasoning: Arguing and Narrating from a Biographical Perspective." New Directions for Child and Adolescent Development 2011, no. 131 (Spring 2011): 1-17.

Habermas, Tilmann, and Susan Bluck. "Getting a Life: The Emergence of the Life Story in Adolescence." Psychological Bulletin 126, no. 5 (September 2000): 748-69.

Harman, Elizabeth. "'I'll Be Glad I Did It' Reasoning and the Significance of Future Desires." Philosophical Perspectives 23, no. 1 (December 2009): 177-99.

_. "Transformative Experiences and Reliance on Moral Testimony." Res Philosophica 92, no. 2 (April 2015): 323-39.

Harrelson, Kevin J. "Narrative Identity and Diachronic Self-Knowledge." Journal of the American Philosophical Association 2, no. 1 (Spring 2016): 164-79.

Horwich, Paul. Asymmetries in Time: Problems in the Philosophy of Science. Cambridge, MA: MIT Press, 1987.

Irvine, William Braxton. A Guide to the Good Life: The Ancient Art of Stoic Joy. Oxford: Oxford University Press, 2009.

Kolodny, Niko. "Which Relationships Justify Partiality? General Considerations and Problem Cases." In Partiality and Impartiality: Morality, Special Relation- 
ships, and the Wider World, edited by Brian Feltham and John Cottingham, 169-93. Oxford: Oxford University Press, 2010.

Lieberman, Charlotte. "Why You Should Stop Being So Hard on Yourself." New York Times, May 22, 2018.

McMahan, Jeff. "Preventing the Existence of People with Disabilities." In Quality of Life and Human Difference, edited by Jerome Bickenback, David Wasserman, and Robert Wachbroit, 142-71. Cambridge: Cambridge University Press, 2005.

Morton, Adam. "Cousins of Regret." In The Moral Psychology of Regret, edited by Anna Gottlieb. Lanham, MD: Rowman and Littlefield, forthcoming.

Nietzsche, Friedrich Wilhelm. The Gay Science. Cambridge: Cambridge University Press, 2001.

Parfit, Derek. Reasons and Persons. Oxford: Oxford University Press, 1984.

Priest, Maura. "Reasonable Regret." In The Moral Psychology of Regret, edited by Anna Gottlieb. Lanham, MD: Rowman and Littlefield, forthcoming.

Salow, Bernhard. "Partiality and Retrospective Justification." Philosophy and Public Affairs 45, no. 1 (Winter 2017): 8-26.

Sandel, Michael J. The Case against Perfection. Cambridge, MA: Harvard University Press, 2007.

Schechtman, Marya. The Constitution of Selves. Ithaca, NY: Cornell University Press, 1996.

Scheffler, Samuel. "Relationships and Responsibilities." Philosophy and Public Affairs 26, no. 3 (July 1997): 189-209.

Wallace, R. Jay. The View from Here: On Affirmation, Attachment, and the Limits of Regret. Oxford: Oxford University Press, 2013.

Williams, Bernard. "Persons, Character, and Morality." In Moral Luck, 1-19. Cambridge: Cambridge University Press, 1981.

Wolf, Susan. "Moral Saints." Journal of Philosophy 79, no. 8 (August 1982): 419-39. Yao, Vida. "Grace and Alienation." Unpublished manuscript. 